\title{
Efficacy of 1-MCP for Modulating the Ethylene Sensitivity of Japanese Persimmon in Relation with Internal Structure
}

\author{
Poly KARMOKER ${ }^{1}$, Wako OBATAKe ${ }^{1}$, Fumina TANAKA ${ }^{2}$ and Fumihiko TANAKA ${ }^{2}$ \\ ${ }^{1}$ Graduate School of Bioresource and Bioenvironmental Sciences, Kyushu University, 744 Motooka, Nishi-ku, \\ Fukuoka 819-0395, Japan \\ ${ }^{2}$ Laboratory of Postharvest Science, Faculty of Agriculture, Kyushu University, 744 Motooka, Nishi-ku, Fukuoka 819-0395, Japan
}

(Received February 20, 2017; Accepted June 6, 2018)

\begin{abstract}
The efficacy of 1-MCP in modulating the ethylene sensitivity of Japanese persimmon (Diospyros kaki) in terms of thermal and structural properties was investigated at $0^{\circ} \mathrm{C}$ and $25^{\circ} \mathrm{C}$. X-ray computed tomography was employed to quantify the structural properties. The physicochemical properties were measured destructively and correlated with X-ray image properties. 1-MCP satisfactorily suppressed the ethylene sensitivity in terms of bio-yield stress, $L^{*}$, and hue angle value at both temperatures. The changes in porosity and thermal conductivity in 1-MCP-treated fruit were smaller than those in control and ethylene-treated fruit. The histogram profile also shifted slightly to a high-density region in 1-MCP-treated fruit. The $L^{*}$ value, hue angle, apparent density, moisture content, bio-yield stress, and TSS were highly correlated with average CT value and standard deviation at both temperatures. Thus, X-ray CT images could be used to quantify the thermal and structural properties, and 1-MCP could suppress the ethylene sensitivity of Japanese persimmon stored at $0^{\circ} \mathrm{C}$ and $25^{\circ} \mathrm{C}$ for 8 and 1 weeks, respectively.
\end{abstract}

Keywords : storage, structural properties, thermal conductivity, X-ray CT

\section{INTRODUCTION}

Japanese persimmon (Diospyros kaki) is a popular fruit in Japan that is native to China and has many varieties. 'Fuyu' is the most common non-astringent variety that is widely cultivated in Japan. Persimmon fruit is the third most produced and exported fruit in Japan, representing 240,600 tons of production and $\$ 2,051,000$ of export (FAOSTAT, 2014). Persimmon fruit has a higher level of sugar value compared with apple, pear, peach, etc. It also has some bioactive compounds including ascorbic acid and condensed tannin (Bubba et al., 2009). The storability and shelf life of persimmon fruit depend on the variety, stage of maturity, and cultivation practices. Fruit softening is a major concern for the persimmon marketing system. The relationship of ethylene biosynthesis in relation with molecular mechanism to reduction of persimmon fruit firmness were documented. It was showed that the ethylene production increased after harvesting and initiated from the calyx; then diffuse to all over the cell tissue followed to loss of fruit firmness (Nakano et al., 2002; 2003). The role of ethylene receptor during development and ripening of persimmon fruit was identified (Pang et al., 2007).

The efficacy of 1-MCP to extend the shelf life during storage has been demonstrated in several fruits. It depends on the concentration of active 1-MCP used, treatment temperature, storage temperature, fruit type, and stage of maturity (Harris et al., 2000; Blankenship and Dole, 2003).
The use of 1-MCP not only delays postharvest ripening but also improves the incidence of some low temperature storage disorders, such as internal browning of avocado by reducing polyphenol oxidase and peroxidase activities (Pesis et al., 2002; Woolf et al., 2005) that were increased with exogeneous ethylene application. The chilling injury and peel pitting of citrus fruits were also minimized by application of $1-\mathrm{MCP}$ at a rate of 50-500 $\mu \mathrm{g} / \mathrm{L}$ (Dou et al., 2005). The fruit firmness could be maintained by 1-MCP (Luo et al., 2009; Pongprasert and Srilaong, 2014). 1-MCP delayed the ripening of persimmon fruit by not only decreasing of ethylene production and respiration rate but also retarding the PME and PG activities (Luo, 2007). But the internal structural changes that could be delayed by 1 MCP are still unknown.

Quality evaluation of fresh fruit and vegetables by non-destructive methods is of growing interest to researchers, because manual operation has limitations such as inconsistency, time consumption, variability, and subjectivity. The quality is evaluated and measured not only by external factors such as color, size, shape, surface blemish, and bruises, but also by internal freshness and disorder. Sometimes the external quality is not altered, but internal changes, such as moisture loss, chemical conversion, cell damage, and internal disorder occur. X-rays, which can penetrate matter, are short wave length $(0.01-10 \mathrm{~nm})$ radiation that have an energy range of $1.92 \times 10^{-17}$ to $1.92 \times$ $10^{-14} \mathrm{~J}$. X-ray computed tomography could be used to measure internal quality, specially the internal disorder. A

Corresponding author: Fumihiko Tanaka, fax: +81-92-802-4636, e-mail: fumit@bpes.kyushu-u.ac.jp 
3D model generated from X-ray CT images may be useful for visualizing the internal changes of intact fruit or vegetables during storage (Donis-gonza et al., 2014). Structuredependent physical properties, such as porosity and moisture content, have a direct relationship with thermal properties. Tanaka et al. (2018a) proposed a model to estimate the porosity, thermal conductivity, and moisture content using X-ray $\mathrm{CT}$. The objective of this paper was to identify the efficacy of 1-MCP on the shelf life and ethylene sensitivity of Japanese persimmon in terms of its thermal and structural properties.

\section{MATERIALS AND METHODS}

Japanese persimmon (Diospyros kaki L.) of optimum maturity were obtained from the JA Chikuzen Asakura, Amagi, Fukuoka, Japan. Fruit with uniform color and average weight of $280 \pm 10 \mathrm{~g}$ (mean \pm S.D.) were selected for the experiment. The fruit were divided into two lots, to be stored at $0^{\circ} \mathrm{C}$ and $25^{\circ} \mathrm{C}$. Both lots contained control, as well as ethylene, 1-MCP, and 1-MCP+ethylene-treated fruit. The fruit for each treatment were packed in a corrugated cardboard box and stored at $0^{\circ} \mathrm{C}$ and $25^{\circ} \mathrm{C}$ for 8 and 4 weeks, respectively. The temperature of the storage room was automatically controlled and additionally a temperature recorder (Thermo Recorder TR-72U, T\&D CORP. JAPAN) for checking the temperature was placed inside the storage room. The mean temperature were recorded as $0 \pm 0.2^{\circ} \mathrm{C}$ and $25 \pm 0.1^{\circ} \mathrm{C}$ (mean \pm S.D.), respectively. Five fruits from each treatment were used for every measurement week and a set of five fruits from each treatment was used for acquisition of X-ray CT images throughout the storage period at both temperatures.

\section{1-MCP treatment}

Harvested persimmon fruit were treated with 1-MCP (Rohm and Haas China Inc., China) within $7 \mathrm{~h}$ after harvesting at a dose of $1 \mathrm{ppm}$ (according to the manual) for 24 $\mathrm{h}$ at $25^{\circ} \mathrm{C}$. A $54 \mathrm{~cm} \times 64 \mathrm{~cm} \times 65 \mathrm{~cm}$ closed glass box, designed with continuous aeration facilities, was used for the 1-MCP treatment. A beaker containing 1-MCP with 200 $\mathrm{mL}$ distilled water was placed in the box and continuously agitated by a magnetic stirrer (MGP-101, SIBATA, Japan). After $24 \mathrm{~h}$ of 1-MCP treatment, half the treated fruits were subjected to ethylene. The other half of treated fruits were packed in a paperboard box, sealed tightly, and placed in storage temperatures of $0^{\circ} \mathrm{C}$ and $25^{\circ} \mathrm{C}$.

\section{Ethylene treatment}

The control and 1-MCP treated persimmon fruit were placed into two separate plastic boxes $(45 \mathrm{~cm} \times 34 \mathrm{~cm} \times 30$ $\mathrm{cm}$ ). Standard ethylene gas (Japan Fine Products Co., Ltd., Japan) was injected at a concentration of $10 \mathrm{ppm}$ into the box and these samples were treated at $25^{\circ} \mathrm{C}$ for $24 \mathrm{~h}$. The samples were then placed in a paper board carton and sealed and stored separately at $25^{\circ} \mathrm{C}$ and $0{ }^{\circ} \mathrm{C}$.

Measurement of moisture content and total soluble solid

The moisture content of each fruit was measured by the vacuum oven drying method at $70^{\circ} \mathrm{C}$ and $-0.1 \mathrm{kPa}$ for $72 \mathrm{~h}$. The total soluble solid (TSS) content was measured according to the method proposed by Majidi et al. (2011), using a digital refractometer (MASTER T, ATAGO CO., LTD., Japan).

\section{Determination of apparent density}

Sample volume $V_{\mathrm{S}}\left(\mathrm{m}^{3}\right)$ was measured by the water displacement method, based on Archimedes' principle, using distilled water at $25^{\circ} \mathrm{C}$. The apparent density $\rho_{\text {ap }}$ $\left(\mathrm{kg} / \mathrm{m}^{3}\right)$ of each fruit was then calculated by the following equation, where $m_{\mathrm{s}}$ represents sample weight $(\mathrm{kg})$ :

$$
\rho_{\text {ap }}=m_{\mathrm{s}} / V_{\mathrm{S}}
$$

Determination of firmness

A penetrometer (Creep Meter RE-3305, YAMADEN Co., Ltd., Japan) equipped with a cylindrical plunger (diameter: $3 \mathrm{~mm}$ ) was used for firmness testing. The sample was divided into two pieces by cutting throughout the circumferential area, to measure the flesh firmness of the fruit. The sample was placed on the stage of the penetrometer and penetrated at a speed of $1 \mathrm{~mm} / \mathrm{s}$. In accordance with the method proposed by Mallikarjunan et al. (2011), the bioyield stress $F\left(\mathrm{~N} / \mathrm{m}^{2}\right)$ was obtained.

Determination of external color

The surface color of the sample was measured based on $L^{*} a^{*} b^{*}$ color system, using a chromameter (CR-200b, KONICA MINOLTA, INC., Japan). The color change was measured by $L^{*}$ value and hue angle value according to the formula:

$$
\text { Hue angle }=\tanh \frac{b^{*}}{a^{*}}
$$

$X$-ray CT image acquisition and image processing

$\mathrm{X}$-ray CT images from five fruits each of the control and treated samples were obtained using an X-ray CT system (Latheta LCT-100, Aloka, Japan) operated at $50 \mathrm{kV}$ and $1 \mathrm{~mA}$ current. The fruit was placed in a holding tube and scanned at $2 \mathrm{~mm}$ pitch width. About $20 \mathrm{~s}$ of time was required to capture the image for each pitch. The scanned images were reconstructed at $-900 \mathrm{HU}$ to $300 \mathrm{HU}$ by Nashita software to create 8 -bit bitmap images $(480 \times 480$ pixels), and the total volume was separated into low-density ( $-900 \mathrm{HU}$ to $-200 \mathrm{HU})$ and high-density $(-200 \mathrm{HU}$ to $+300 \mathrm{HU}$ ) regions to measure the progress of high-density regions during the storage period. The average CT value for flesh part was measured using Nashita software. The external pixels were manually removed using the paintbrush tool in Image (NIH, USA), to produce an Xray absorption histogram and to measure the standard deviation and peak height at a $0-255$ gray scale (GS) threshold value. The conversion equation for $\mathrm{CT}$ value in GS to $\mathrm{CT}$ in $\mathrm{HU}$ is as follows:

$$
\mathrm{CT} \text { value } \mathrm{HU}=\frac{\mathrm{GS} \text { value } * 1200}{255}-900
$$

An X-ray absorption histogram comparing the pixel ratio and gray scale (GS) value was produced, incorporating all acquired images during the storage period, and was used for comparison among the control, and ethylene, 1-MCP and 1-MCP+ethylene-treated fruit. All X-ray computed image data were calibrated against distilled water as a standard. Porosity and thermal conductivity were estimated according to the method proposed by Tanaka et al. (2018a).

Statistical analysis 
Pair wise one-way ANOVA for means based on Tukey's method was performed on the data for moisture content, TSS, apparent density, bio-yield stress and external color ( $L^{*}$ and hue angle value) data were used to identify the differences among the control and treated fruit during storage. All statistical analyses were performed with R ver. 3.1.2 (R Foundation for Statistical Computing, Vienna, Austria). Regression analysis with 95\% confident level was done to correlate the image properties to the quality parameter observed during storage.
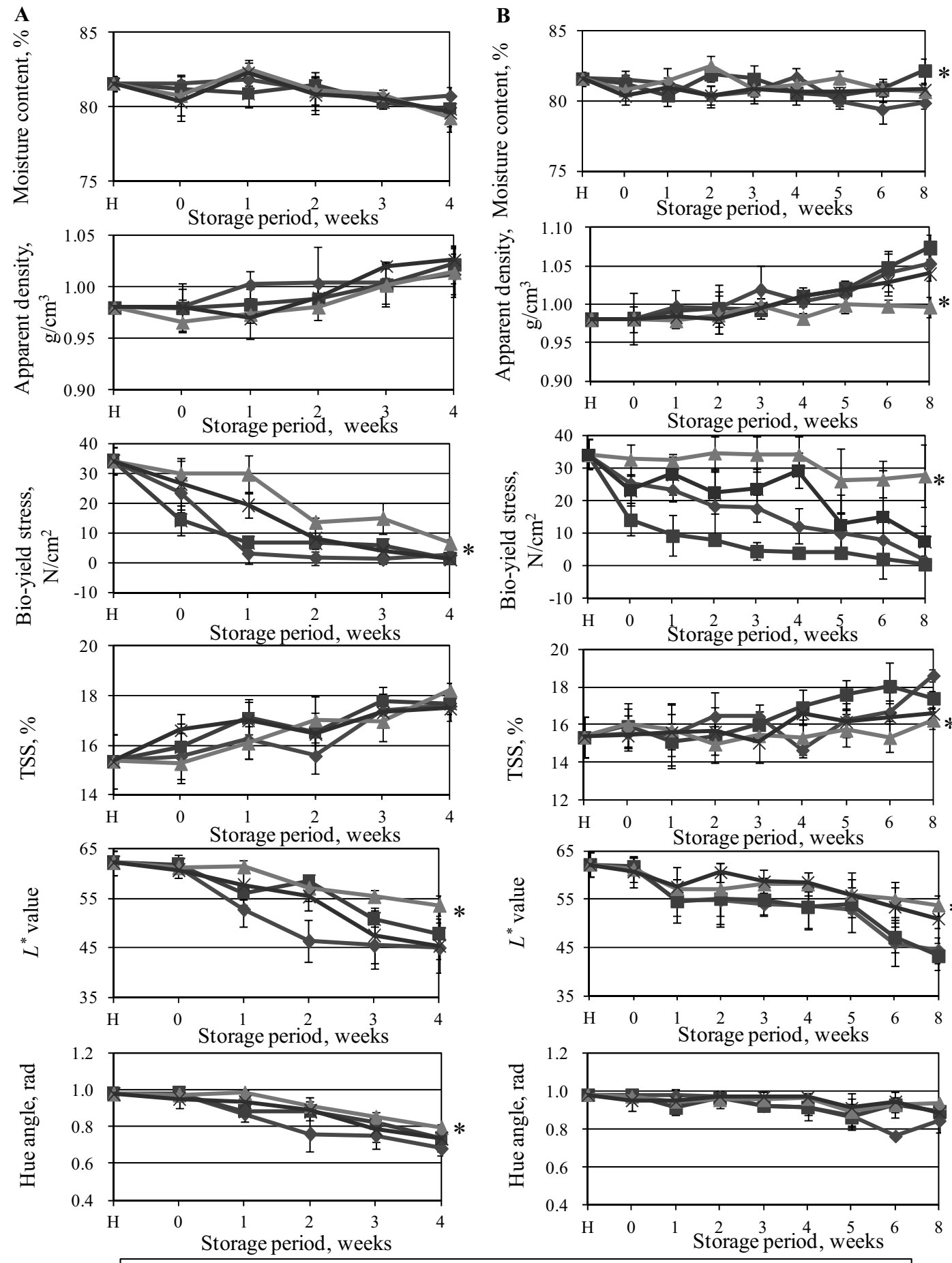

Quality parameters observed during storage

Figure 1 shows the physicochemical properties of persimmon fruit in the control, and ethylene, 1-MCP and 1$\mathrm{MCP}+$ ethylene-treated samples during storage at $25^{\circ} \mathrm{C}$ and $0^{\circ} \mathrm{C}$. Quality indicators, such as the moisture content, apparent density, bio-yield stress, TSS, and external color of the persimmon fruit were measured over the storage pe-
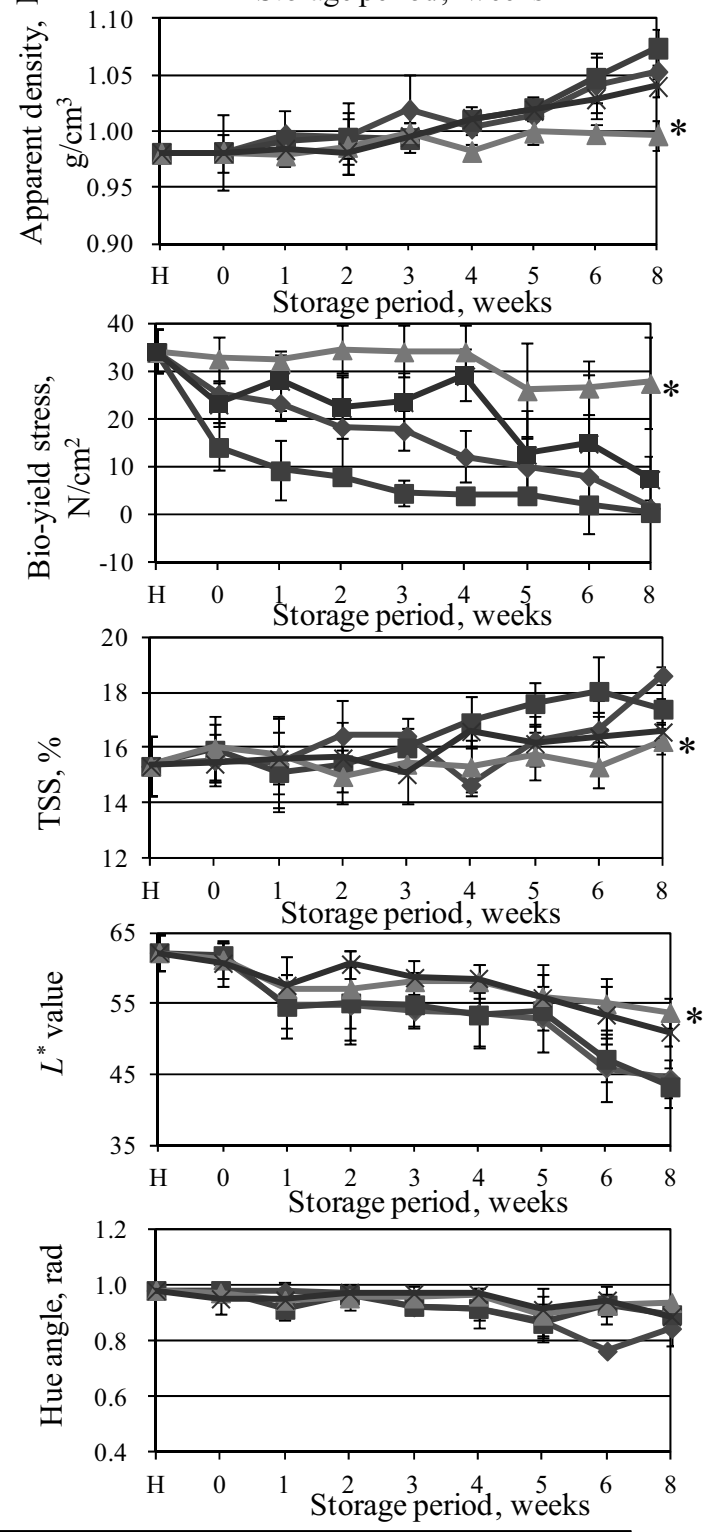

$\mathrm{H}:$ Harvest $\multimap$ Control $\longrightarrow$ Ethylene $-1-\mathrm{MCP} \leftarrow 1-\mathrm{MCP}+$ Ethylene $* P \leq 0.05$

Fig. 1 Physicochemical properties of persimmon fruit during storage period: A $\left(25^{\circ} \mathrm{C}\right)$, B $\left(0^{\circ} \mathrm{C}\right)$, Error bars indicate S.D. 
riod at $25^{\circ} \mathrm{C}$ and $0^{\circ} \mathrm{C}$. Moisture content of all the control and treated samples declined over the storage period at 25 ${ }^{\circ} \mathrm{C}$. The moisture content was almost constant in the control, 1-MCP and 1-MCP+ethylene treated samples at $0^{\circ} \mathrm{C}$. At the end of the storage period, the moisture content of the ethylene treated fruit was slightly elevated at $0^{\circ} \mathrm{C}$. There was not a significant difference among all samples. The increase and decrease of moisture content were caused by the combination of the several metabolic activity such as respiration, transpiration and evaporation. In ethylene treated fruit stored at $0^{\circ} \mathrm{C}$, the evaporation might be lower, however water was produced ripening. It is the balance of these phenomenon.

The apparent density of all treated samples increased at both temperatures. At the end of the storage period, the ethylene treated fruit had the highest and 1-MCP treated fruit had the lowest apparent density at both temperatures. During storage, the shrinkage of external volume made the fruit more dense compare with initial state. As the volume of 1-MCP treated fruit decreased slowly compared with other treated and control fruit at both temperatures, the volume decreased minimally. Therefore, the increment of apparent density in 1-MCP treated fruit was lower than that of other treated fruits. Apparent density of 1-MCP treated fruit was nearly constant during storage at $0^{\circ} \mathrm{C}$. This results identified that 1-MCP could satisfactorily suppress the metabolic activity at $0^{\circ} \mathrm{C}$ as the apparent density didn't change through the storage period.

The firmness of the fruit showed a sharp decrease immediately after harvest. In the ethylene treated fruit, the firmness declined the most after harvest, and it was near half the harvesting firmness during the treatment period of 24 h. 1-MCP treated fruit had good firmness value during 1 and 8 weeks at the storage temperature of $25^{\circ} \mathrm{C}$ and $0^{\circ} \mathrm{C}$, respectively, as they had nearly same firmness at harvest. The firmness of 1-MCP treated fruit was almost constant over the total storage period at $0^{\circ} \mathrm{C}$ and significantly $(P \leq 0.05)$ different from other treated and control fruit at both temperatures. Firmness is the most important quality factor for persimmon fruits because it has a direct effect on consumer acceptability. Water loss and cell wall modification in blueberry causes firmness loss, and sufficient shrinkage and water loss have been confirmed by the magnetic resonance image method (Paniagua et al., 2013). Murayama et al. (2006) suggested that depolymerization of pectic and hemicellulosic polysaccharides was related to firmness loss in long term storage of pear. The depolymerization caused by enzyme activity was highly correlated with ethylene production in apple fruit and it made the fruit soften (Gwanpua et al., 2014). 1-MCP could bind the ethylene receptor to reduce ethylene production and delay the declination of fruit firmness during storage (Guillén et al., 2007). In this study, as the firmness of persimmon fruit in terms of bio-yield stress sharply declined during ethylene treatment, it was confirmed that persimmon fruit was highly sensitive to ethylene. As for 1-MCP treated fruit, the firmness was kept during storage because 1-MCP bound to the receptor.

The TSS increased over the storage period at both temperatures. The TSS of 1-MCP treated fruit was significantly lower compared with control and ethylene treated fruit at $0^{\circ} \mathrm{C}$ temperature at the end of 8 week storage period. During ripening, soluble sugar content was increased with gradually decreasing acid content (Fan et al., 2017). The TSS content of 1-MCP treated fruit slowly increased; however, there was no difference at $25^{\circ} \mathrm{C}$ during storage. As for 1-MCP treated fruit stored at $0^{\circ} \mathrm{C}$, TSS was maintained over the storage period. The results indicated that the $1-\mathrm{MCP}$ treatment could delay ripening of the stored persimmon fruit.

The color indices of all control and treated fruit were measured as $L^{*}$ and hue angle values. The $L^{*}$ and hue angle values decreased over time in all fruits, and the 1-MCP treated fruit showed a significantly higher value at the end of 4 and 8 weeks for the corresponding temperatures of 25 ${ }^{\circ} \mathrm{C}$ and $0^{\circ} \mathrm{C}$, respectively. The ethylene treated fruit had a better performance in terms of $L^{*}$ and hue angle values compared with the control and 1-MCP+ethylene-treated fruit at $25^{\circ} \mathrm{C}$, whereas it performed the same as the control fruit at $0^{\circ} \mathrm{C}$. The external color changed during ripening with the combination of internal constitutional modification. 1-MCP might influence the retention of external color at both temperatures.

Here, the control and ethylene treated fruit showed the same pattern, whereas the 1-MCP and 1-MCP+ ethylene treated fruit showed a different pattern in terms of all quality parameters observed. 1-MCP treated fruit were significantly different $(P \leq 0.05)$ from other treatment fruit for the most important parameters, firmness and color, at both temperatures. 1-MCP has a prominent effect on the postharvest quality of some fruits and vegetables, as it blocks the production of ethylene receptors (Sisler et al., 1996; Watkins, 2006), and the role of ethylene receptors during postharvest ripening and senescence are well documented (Agarwal et al., 2012). 1-MCP have been used satisfactorily for slowing the peel yellowing of pear (Cheng et al., 2012) and bitter melon (Han et al., 2015), delaying the postharvest ripening of peach fruit by postponing the climacteric peak in respiration, enhancing firmness, increasing glutathione peroxidase (GPX) activity, and upregulating PpaGPX expression. PpaGPXs had a more important regulatory function in the late stages of peach fruit ripening (Huan et al., 2016). Therefore, as expected, 1MCP showed a good response in terms of delayed ripening after maturation of fruit, and 1-MCP+ethylene-treated fruit showed better performance compared with the control and ethylene-treated fruit during the storage period at both temperatures.

\section{$X$-ray computed tomography image properties}

The representative internal images for control and all treated fruit are shown in Fig. 2 for both temperatures. These images were produced by reconstructing of X-ray images at a threshold value of $-900 \mathrm{HU}$ to $+300 \mathrm{HU}$ using Nashita software. The same type of internal image was observed in all fruit for initial stage, 4 weeks at $25^{\circ} \mathrm{C}$, and 8 weeks at $0^{\circ} \mathrm{C}$. Therefore, the changes in internal structure at $0^{\circ} \mathrm{C}$ temperature could be suppressed upto 8 weeks in compared with that of 4 weeks at $25^{\circ} \mathrm{C}$. It was also ob- 


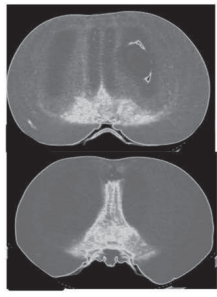

Control

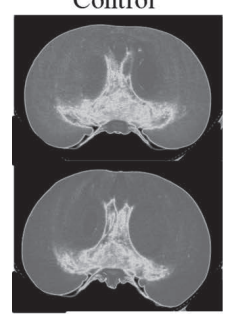

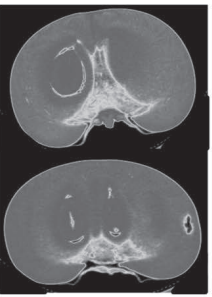

Ethylene

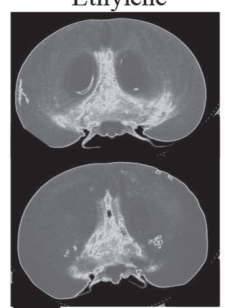

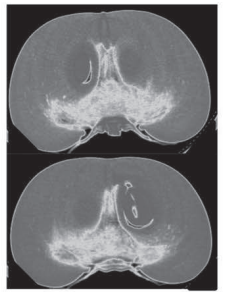

$1-\mathrm{MCP}$

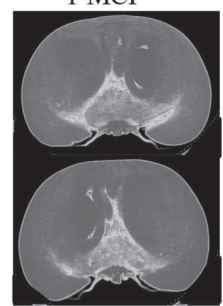

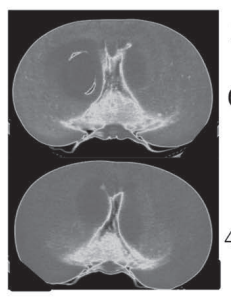

$25^{\circ} \mathrm{C}$

$25^{\circ} \mathrm{C}$

$300 \mathrm{HU}$

1-MCP+Ethylene $0^{\circ} \mathrm{C}$

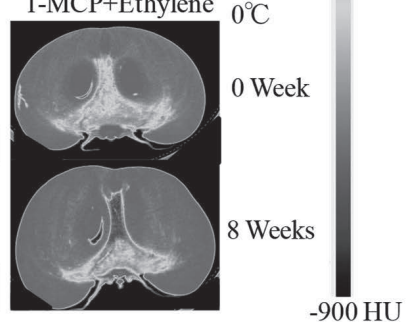

Fig. 2 Representative X-ray CT images for all treated fruits during storage period at both temperatures.

$$
\text { A }
$$

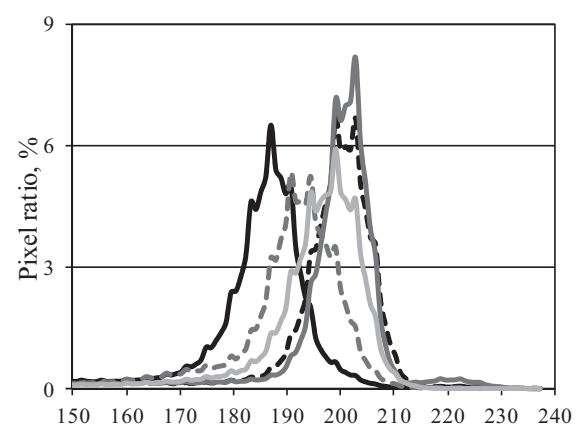

Gray Scale value
B

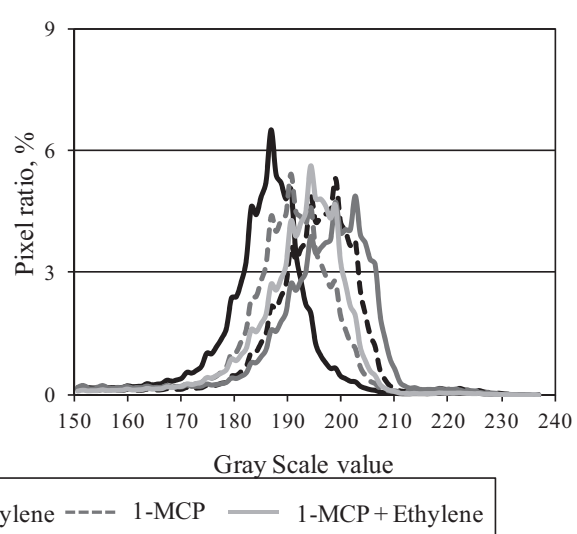

Fig. 3 Histogram profile for Persimmon stored at $25^{\circ} \mathrm{C}(\mathrm{A})$ and $0^{\circ} \mathrm{C}(\mathrm{B})$ for 4 and 8 weeks.

served that the control and ethylene treated fruit had a greater amount of high-density regions at both temperatures compared with the 1-MCP and 1-MCP+ethylene treated fruit. Though ethylene treated fruit showed higher density in higher CT value region, gas filled void spaces progressed through some flesh regions during the storage period at both temperatures. It was found that 1-MCP treated fruit had the small tendency to shift higher CT value region during storage.

The X-ray absorption histogram was produced for the fruits at harvest and the end of the storage period at both temperatures. The histogram profiles for all fruit were compared with the harvest histogram profiles, as shown in Fig. 3. The average CT value and standard deviation of histogram were obtained over the storage period of the fruit, incorporating all slices of the fruit. It was observed that the histogram profile shifted to the higher GS value region at both temperatures. This results indicate higher X-ray CT absorption occurred at the end of storage period compared to the harvest. In the control and ethylene treated fruit, the profiles showed the most apparent shift from the original profile at harvesting. The peak height also increased the most in the ethylene treated fruit and near constant in control fruit. On the contrary, the 1-MCP treated fruit had a slightly lower peak height and it shifted to a higher GS value from the initial position of the peak at harvest. The patterns of histogram for all fruits showed the same rightward shifting toward higher gray scale value region at 4 weeks in $25^{\circ} \mathrm{C}$ and 8 weeks at $0^{\circ} \mathrm{C}$, except for the control and ethylene treated fruit. At $25^{\circ} \mathrm{C}$, the peak height of the histogram increased in the ethylene treated fruit, whereas it decreased at $0^{\circ} \mathrm{C}$ for all fruits. It means that low temperature could delay the changes in the initial internal structure. Increasing peak height and the rightward shifting of histogram profile measures the increment of density which depends on the moisture content and TSS. During storage, the moisture content and TSS increased most in ethylene treated fruit at $25^{\circ} \mathrm{C}$, which could be the reason for higher absorption of X-ray. Barcelon et al. (1999) showed a positive linear relationship of average CT number to moisture content and density of mango fruit during storage. The TSS of all treated and control fruit was increased at both temperature may influenced the higher X-ray absorption. This result was validated by acquiring X-ray $\mathrm{CT}$ images of $0 \%, 5 \%, 10 \%$, and $15 \%$ sucrose solution. The peak increased in height and the histogram profile shifted to the right with the increasing concentration of sucrose in the solution. The histogram profile of sucrose solution was 
shown in the supplementary Fig. 1 and the images of sucrose solution in a tube was acquired by X-ray CT.

Image properties, such as average CT value, standard deviation, peak height, and progress in high-density pixel volume, were quantified over the storage period at both temperatures, as shown in Fig. 4. The average CT value increased during the storage period at both temperatures. 1MCP treated fruit had a lower CT value compared with other treated samples. The ethylene treated fruit had significantly higher CT values at both temperatures. The lower changes in average CT value indicated that lower changes occurred in the internal constituent and structural network. The average CT value is the index of internal composition and the structural pattern of the component, as it has a direct relationship with both (Barcelon et al., 1999). The standard deviation of the histogram profile also increased at both temperatures for the control and treated fruit. At $0^{\circ} \mathrm{C}$, the increments in standard deviation and average $\mathrm{CT}$ ab- sorption were slower than the values obtained at $25^{\circ} \mathrm{C}$. The increment of standard deviation indicated the porosity progress during storage. The peak height of the ethylene treated fruit increased the most at $25^{\circ} \mathrm{C}$, whereas it decreased slightly at $0^{\circ} \mathrm{C}$ after 8 weeks of harvest. The volume of the high-density region increased the most in the ethylene treated fruit at $25^{\circ} \mathrm{C}$ and was significantly higher compared with the control, 1-MCP and 1-MCP+ethylene treated samples. The volume of high-density regions in the 1-MCP-treated fruit changed the least from the original volume at both temperatures. The standard deviation, highdensity volume, peak height, and average CT value indicated the constituents of the fruit and its distributions. Therefore, it was concluded that 1-MCP could maintain the consistency of the fruit over the storage period at both temperatures, compared with the control and other treatments.
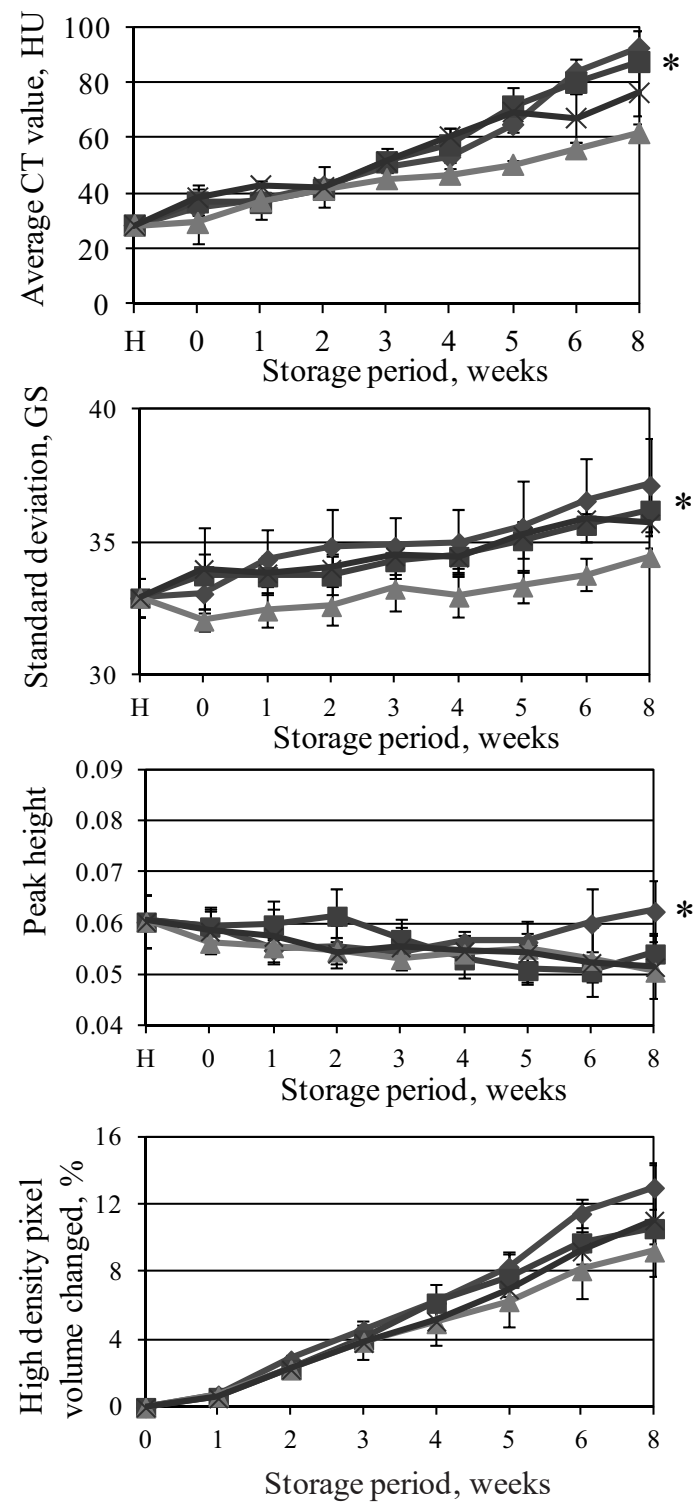

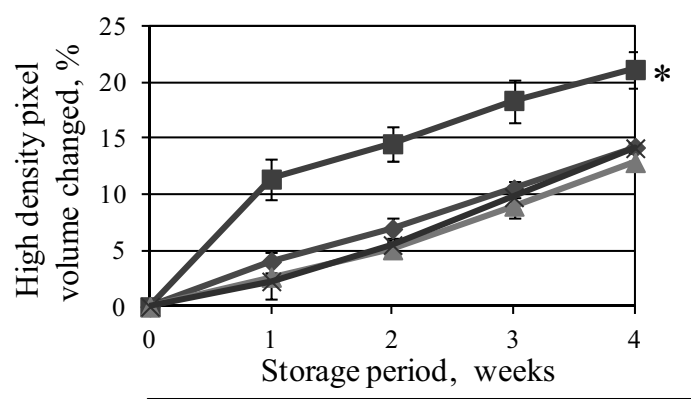

H: Harvest $\multimap$ Control $\multimap$ Ethylene

$\leftarrow 1-\mathrm{MCP} \rightleftharpoons 1-\mathrm{MCP}+$ Ethylene $* P \leq 0.05$

Fig. 4 X-ray CT image properties during storage: A $\left(25^{\circ} \mathrm{C}\right), \mathrm{B}\left(0^{\circ} \mathrm{C}\right)$; Error bars indicate S.D. 
Table 1 Relationship with quality parameter to average CT value and standard deviation.

\begin{tabular}{|c|c|c|c|c|c|}
\hline \multirow{2}{*}{\multicolumn{2}{|c|}{ Quality parameter }} & \multicolumn{2}{|l|}{ Control } & \multicolumn{2}{|l|}{ All fruit } \\
\hline & & Equation & $\mathrm{r}$ & Equation & $\mathrm{r}$ \\
\hline$L^{*}$ & $\begin{array}{l}25^{\circ} \mathrm{C} \\
0^{\circ} \mathrm{C}\end{array}$ & $\begin{array}{l}L^{*}=-0.3935 \overline{C T}+70.89 \\
L^{*}=-6.41 S D_{\mathrm{GS}}+270.81 \\
L^{*}=-0.2515 \overline{C T}+.67295 \\
L^{*}=-4.13 S D_{\mathrm{GS}}+197.95\end{array}$ & $\begin{array}{l}-0.87 \\
-0.92 \\
-0.95 \\
-0.99\end{array}$ & $\begin{array}{l}L^{*}=-0.298 \overline{C T}+69.372 \\
L^{*}=-3.5 S D_{\mathrm{GS}}+176.58 \\
L^{*}=-0.2443 \overline{C T}+68.291 \\
L^{*}=-3.35 S D_{\mathrm{GS}}+170.35\end{array}$ & $\begin{array}{l}-0.85 \\
-0.70 \\
-0.88 \\
-0.83\end{array}$ \\
\hline Apparent density & $\begin{array}{l}25^{\circ} \mathrm{C} \\
0^{\circ} \mathrm{C}\end{array}$ & $\begin{array}{l}\rho_{a p}=0.0007 \overline{C T}+0.96 \\
\rho_{a p}=0.0098 \quad S D_{\mathrm{GS}}+0.66 \\
\rho_{a p}=0.0011 \overline{C T}+0.95 \\
\rho_{a p}=0.014 S D_{\mathrm{GS}}+0.41\end{array}$ & $\begin{array}{l}0.88 \\
0.83 \\
0.96 \\
0.95\end{array}$ & $\begin{array}{l}\rho_{a p}=0.0008 \overline{C T}+0.95 \\
\rho_{a p}=0.0104 \quad S D_{\mathrm{GS}}+0.63 \\
\rho_{a p}=0.0013 \overline{C T}+0.94 \\
\rho_{a p}=0.017 S D_{\mathrm{GS}}+0.41\end{array}$ & $\begin{array}{l}0.79 \\
0.74 \\
0.93 \\
0.88\end{array}$ \\
\hline Bio-yield stress & $\begin{array}{l}25^{\circ} \mathrm{C} \\
0^{\circ} \mathrm{C}\end{array}$ & $\begin{array}{ll}F=-0.60 & \overline{C T}+39.67 \\
F=-6.86 & S D_{\mathrm{GS}}+252.46 \\
F=-0.42 & \overline{C T}+39.53 \\
F=-6.78 & S D_{\mathrm{GS}}+253.81\end{array}$ & $\begin{array}{l}-0.74 \\
-0.69 \\
-0.96 \\
-0.94\end{array}$ & $\begin{array}{ll}F=-0.55 & \overline{C T}+40.45 \\
F=-9.39 & S D_{\mathrm{GS}}+331.51 \\
F=-0.46 & \overline{C T}+43.41 \\
F=-7.47 & S D_{\mathrm{GS}}+275.6\end{array}$ & $\begin{array}{l}-0.77 \\
-0.75 \\
-0.71 \\
-0.80\end{array}$ \\
\hline TSS & $\begin{array}{l}25^{\circ} \mathrm{C} \\
0^{\circ} \mathrm{C}\end{array}$ & $\begin{array}{l}S=0.051 \overline{C T}+14.03 \\
S=0.79 S D_{\mathrm{GS}}-10.37 \\
S=0.04 \overline{C T}+14.09 \\
S=0.59 S D_{\mathrm{GS}}-4.43\end{array}$ & $\begin{array}{l}0.96 \\
0.97 \\
0.76 \\
0.73\end{array}$ & $\begin{array}{l}S=0.042 \overline{C T}+14.64 \\
S=0.62 \quad S D_{\mathrm{GS}}-5.02 \\
S=0.04 \quad \overline{C T}+14.05 \\
S=0.51 \quad S D_{\mathrm{GS}}-1.38\end{array}$ & $\begin{array}{l}0.82 \\
0.87 \\
0.78 \\
0.71\end{array}$ \\
\hline
\end{tabular}

$L^{*}$ : Brightness value, Rad: Radian, $\rho_{a p}$ : Apparent density, $M$ : Moisture content, $F$ : bio-yield stress, $S$ : Total soluble solid, $S D_{G S}:$ Standard deviation (Gray scale value), $\overline{C T}$ : average CT value; r: correlation coefficient.

\section{Relationship between X-ray CT image properties and} physicochemical properties

To investigate the relationship between X-ray CT image properties and physicochemical properties, we used all control and treated fruit data at $25^{\circ} \mathrm{C}$ and $0{ }^{\circ} \mathrm{C}$ temperatures. There was a linear relationship of $L^{*}$ value, hue angle, apparent density, moisture content, bio-yield stress, and TSS with standard deviation and average CT value. These relationships, along with the correlation coefficient (r), are shown in Table 1. It was observed that higher correlations existed in the control fruit compared with all treatments, as expected. Because control fruit undergoes the regular metabolic activity during storage, whereas other fruit were subjected to ethylene, 1-MCP and 1-MCP+ethylene. 1-MCP treated fruit was changed minimum, whereas maximum changed occurred in ethylene treated fruit. Therefore, there was the big difference in control and treated fruits, makes the $\mathrm{R}$ value small compared to only control fruit. Tanaka et al. (2018b) showed the positive correlation of average CT value to apparent density for cucumber during storage. $\mathrm{X}$ ray absorption depends on the constituent and the dispersion network of solid, liquid, and air spaces inside the fruits. The density-dependent properties influence the Xray absorption the most (Chen and Sun, 1991). Tanaka et al. (2018a) proposed a porosity and thermal conductivity model for fresh persimmon, but this model could be used for external color ( $L^{*}$ and hue angle), density, moisture content, TSS, and firmness in terms of bio-yield stress distribution of persimmon fruit during storage.

Prediction of the changes in porosity and thermal conductivity based on X-ray CT value during storage
Tanaka et al. (2018a) proposed a model for prediction of physical properties using X-ray CT devices with high and normal-resolution. The model could accurately predict the porosity and thermal conductivity distributions in an intact persimmon fruit. The porosity and thermal conductivity of persimmon were estimated in the present study in accordance with the model proposed by Tanaka et al. (2018a). The predicted results for the porosity and thermal conductivity of the fruit are shown in Fig. 5 at both temperatures. It is a little difficult to acquire accurate measurement values for fruit flesh porosity; however, Tanaka et al. (2018a) solved this issue by extracting gas void space from reconstructed three-dimensional microscale structure of cell tissue based on high-resolution X-ray CT images. The predicted porosity of fruit increased over the storage period for all treatments and conditions, as shown in Fig. 5. At $25^{\circ} \mathrm{C}$, the porosity increased 1.5 times in the control and 1-MCP+ethylene treated fruit, whereas a two-fold increase was observed in the ethylene treated fruit compared with the 1-MCP treated fruit. The same pattern of porosity was found at $0^{\circ} \mathrm{C}$ for all control and treated fruits, but it could delay the increment of porosity to 4 weeks from the porosity observed at $25^{\circ} \mathrm{C}$. Porosity has a significant effect on the structural properties of the fruits during storage period. The porosity of gumbo and apple fruit increased over the storage period (Akar and Aydin, 2005; Herremans et al., 2013), which had a direct relationship with the gas diffusivity and respiratory metabolism of the fruit.

Tanaka et al. (2018a) also provided a prediction model for thermal conductivity, by combining X-ray CT image data acquired by high and normal-resolution devices 
A
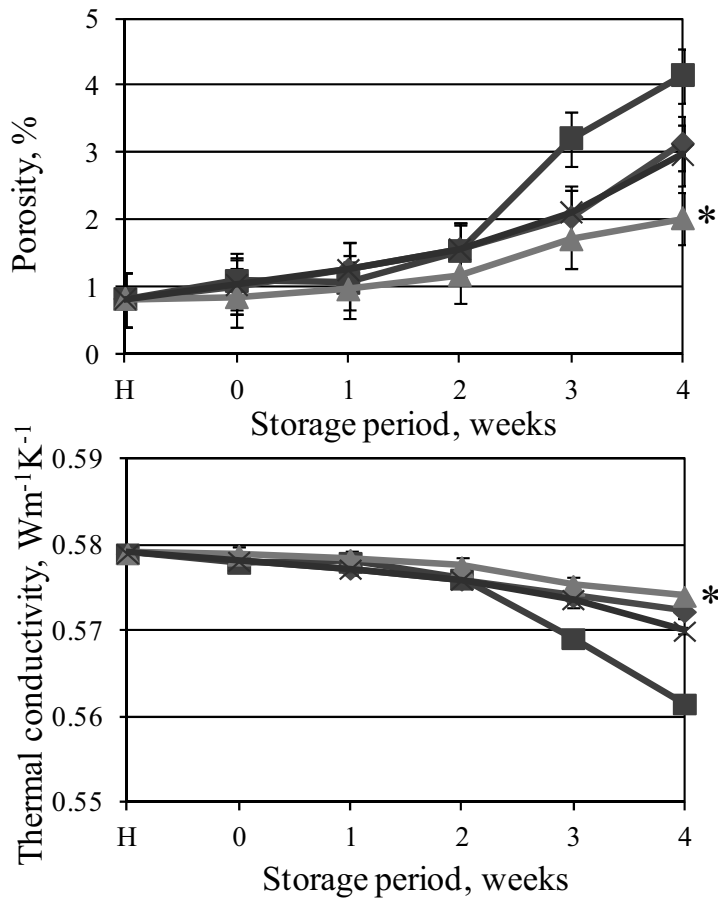

B
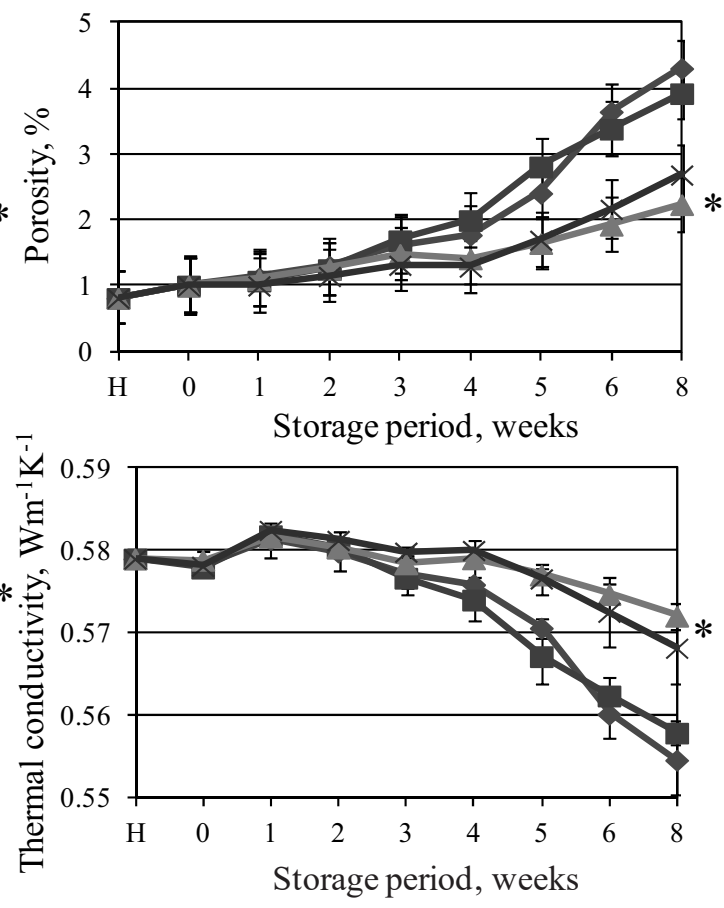

$\mathrm{H}:$ Harvest $\multimap$ Control $\multimap$ Ethylene $\leftarrow 1-\mathrm{MCP} \nsucc 1-\mathrm{MCP}+$ Ethylene $* P \leq 0.05$

Fig. 5 Porosity and thermal conductivity predicted by X-ray CT: A $\left(25^{\circ} \mathrm{C}\right), \mathrm{B}\left(0^{\circ} \mathrm{C}\right)$; Error bars indicate S.D.

and micro-scale CFD simulation. The predicted thermal conductivity decreased at both temperatures, as shown in Fig. 5. The changes in the 1-MCP-treated fruit were the lowest in terms of thermal conductivity. Thermal conductivity depends on the internal constituents and obviously on the structural components, such as density, moisture content, and porosity. The 1-MCP-treated fruit changed the least compared with the control and other treated fruits at both temperatures. In other words, thermal conductivity did not change much in the 1-MCP-treated fruit over the storage period. The predicted thermal conductivity of persimmon fruit was well matched with the thermal conductivity $(0.50 \mathrm{~W} /(\mathrm{m} \mathrm{K}))$ measured by Hara et al. (2014) and the thermal conductivity $(0.563 \pm 0.002 \mathrm{~W} /(\mathrm{m} \mathrm{K}))$ measured by Tanaka et al. (2018a).

Therefore, these models, involving X-ray CT, could be used for the determination of porosity and thermal conductivity in persimmon fruit, without destruction, over the storage period.

\section{CONCLUSION}

It was concluded that 1-MCP could suppress the ethylene sensitivity in terms of firmness of persimmon fruit during storage at $25^{\circ} \mathrm{C}$ (slightly) and $0^{\circ} \mathrm{C}$ (strongly) for 1 and 8 weeks, respectively. The low temperature of storage could not retain the firmness of ethylene treated persimmon fruit. 1-MCP-treated fruit had a lower change in internal structure in comparison with control, ethylene and 1$\mathrm{MCP}+$ ethylene treated fruit at both temperature. For 1MCP treated fruit, the minimum changes in the porosity and thermal conductivity were estimated over the storage period. 1-MCP+ethylene-treated fruit had a better performance compared with control and ethylene-treated fruit in all aspects. The changes in internal structure could be seen using X-ray CT images throughout the storage period. The average CT value and its standard deviation were highly correlated with the $L^{*}$ value, hue angle, apparent density, moisture content, TSS, and bio-yield stress. It might be concluded that 1-MCP could satisfactorily obstruct ethylene sensitivity of Japanese persimmon in relation with its internal structure.

\section{ACKNOWLEDGEMENTS}

This work was partially supported by JSPS KAKENHI Grant Number JP26292135, JP 17H03899 and 1-MCP was provided by the Rohm and Haas China Inc.

\section{REFERENCE}

Agarwal, G., Choudhary, D., Singh, V.P., Arora, A. 2012. Role of ethylene receptors during senescence and ripening in horticultural crops. Plant Signal. Behav. 7: 827-846.

Akar, R., Aydin, C. 2005. Some physical properties of gumbo fruit varieties. J. Food Eng. 66: 387-393.

Barcelon, E.G., Tojo, S., Watanabe, K. 1999. X-ray computed tomography for internal quality evaluation of peaches. J. Agric. Engng Res. 73: 323-330.

Blankenship, M., Dole, J.M. 2003. 1-Methylcyclopropene: a review. Postharvest Biol. Technol. 28: 1-25.

Bubba, M. Del, Giordani, E., Pippucci, L., Cincinelli, A., Checchini, L., Galvan, P. 2009. Changes in tannins, ascor- 
bic acid and sugar content in astringent persimmons during ontree growth and ripening and in response to different postharvest treatments. J. Food Composition and Analysis 22: 668677.

Chen, P., Sun, Z. 1991. A review of non-destructive methods for quality evaluation and sorting of agricultural products. J. Agric. Eng. Res. 49: 85-98.

Cheng, Y., Dong, Y., Yan, H., Ge, W., Shen, C., Guan, J., Liu, L., Zhang, Y. 2012. Effects of 1-MCP on chlorophyll degradation pathway-associated genes expression and chloroplast ultra structure during the peel yellowing of Chinese pear fruits in storage. Food Chem. 135: 415-422.

Donis-gonza, I.R., Guyer, D.E., Pease, A., Barthel, F. $2014 . \quad$ Internal characterisation of fresh agricultural products using traditional and ultrafast electron beam X-ray computed tomography imaging. Biosyst. Eng. 7: 104-113.

Dou, H., Jones, S., Ritenour, M. 2005. Influence of 1-MCP application and concentration on post-harvest peel disorders and incidence of decay in citrus fruit. J. Hortic. Sci. Biotechnol. 80: 786-792.

Fan, X., Zhao, H., Wang, X., Cao, J. 2017. Sugar and organic acid composition of apricot and their contribution to sensory quality and consumer satisfaction. Sci. Hortic. (Amsterdam) 255: 553-560.

FAOSTAT. 2014. Food and Agricultural Organization of the United Nation. http://www.fao.org/faostat/en/\#data/QC 25/05/ 2018.

Guillén, F., Castillo, S., Zapata, P.J., Martínez-Romero, D., Serrano, M., Valero, D. 2007. Efficacy of 1-MCP treatment in tomato fruit. 1. Duration and concentration of 1-MCP treatment to gain an effective delay of postharvest ripening. Postharvest Biol. Technol. 43: 23-27.

Gwanpua, S.G., Buggenhout, S. Van, Verlinden, B.E., Christiaens, S., Shpigelman, A., Vicent, V., Kermani, Z.J., Nicolai, B.M., Hendrickx, M., Geeraerd, A. 2014. Pectin modifications and the role of pectin-degrading enzymes during postharvest softening of Jonagold apples. Food Chem. 158: 283-291.

Hara, K., Umeno, Y., Tanaka, F., Akasaka, Y., Uchino, T. 2014. Three dimensional heat and mass transfer modeling of persimmon fruit based on X-ray CT images. The proceedings of the 73rd Annual Meeting of Japanese Society of Agricultural Machinery and Food Engineers, The University of Ryukyu, May 2014.

Han, C., Zuo, J., Wang, Q., Xu, L., Wang, Z., Dong, H., Gao, L. 2015. Effects of 1-MCP on postharvest physiology and quality of bitter melon (Momordica charantia L.). Sci. Hortic. 182: 86-91.

Herremans, E., Verboven, P., Bongaers, E., Estrade, P., Verlinden, B.E., Wevers, M., Hertog, M.L.A.T.M., Nicolai, B.M. 2013. Characterisation of "Braeburn" browning disorder by means of X-ray micro-CT. Postharvest Biol.Technol. 75: 114-124.

Harris, D.R., Seberry, J.A., Wills, R.B.H. Spohr, L.J. $2000 . \quad$ Effect of fruit maturity on efficiency of 1-methylcyclopropene to delay the ripening of bananas. Postharvest Biol.Technol. 20: 303-308.

Huan, C., Jiang, L., An, X., Kang, R., Yu, M., Ma, R., Yu, Z. 2016. Potential role of glutathione peroxidase gene family in peach fruit ripening under combined postharvest treatment with heat and 1-MCP. Postharvest Biol. Technol. 111: 175184.

Luo, Z. 2007. Effect of 1-methylcyclopropene on ripening of postharvest persimmon (Diospyros kaki L.) fruit. LWT - Food Sci. Technol. 40: 285-291.

Luo, Z., Xie, J., Xu, T., Zhang, L. 2009. Delay ripening of "Qingnai" plum (Prunus salicina L.) with 1-methylcyclopropene. Plant Sci. 177: 705-709.

Majidi, H., Minaei, S., Almasi, M., Mostofi, Y. 2011. Total soluble solids, titratable acidity and repining index of tomato in various storage conditions. Aust. J. Basic Appl. Sci. 5: $1723-1726$.

Mallikarjunan, P. K. 2011. Physical measurements. In "Handbook of Frozen Food Processing and Packaging" (ed. by Sun, D.W.), CRC Press, Boca Raton, FL, p 549-562.

Murayama, H., Katsumata, T., Endou, H., Fukushima, T., Sakurai, N. 2006. Effect of storage period on the molecular-mass distribution profile of pectic and hemicellulosic polysaccharides in pears. Postharvest Biol. Technol. 40: 141-148.

Nakano, R., Inoue, S., Kubo, Y., Inaba, A. 2002. Water stressinduced ethylene in the calyx triggers autocatalytic ethylene production and fruit softening in 'Tonewase' persimmon grown in a heated plastic-house. Postharvest Biol. Technol. 25: 293-300.

Nakano, R., Ogura, E., Kubo, Y., Inaba, A. 2003. Ethylene biosynthesis in detached young persimmon fruits is initiated in calyx and modulated by water loss from the fruit. Plant Physiol. 13: $276^{-286 .}$

Paniagua, A.C., East, A.R., Hindmarsh, J.P., Heyes, J.A. 2013. Moisture loss is the major cause of firmness change during postharvest storage of blueberry. Postharvest Biol.Technol. 79: $13-19$

Pang, J.H., Ma, B., Sun, H.J., Ortiz, G.I., Imanishi, S., Sugaya, S., Gemma, H., Ezura, H. 2007. Identification and characterization of ethylene receptor homologs expressed during fruit development and ripening in persimmon (Diospyros kaki Thumb.). Postharvest Biol. Technol. 44: 195-203.

Pesis, E., Ackerman, M., Ben-Arie, R., Feygenberg, O., Feng, X., Apelbaum, A., Goren, R., Prusky, D. 2002. Ethylene involvement in chilling injury symptoms of avocado during cold storage. Postharvest Biol. Technol. 24: 171-181.

Pongprasert, N., Srilaong, V. 2014. A novel technique using 1MCP microbubbles for delaying postharvest ripening of banana fruit. Postharvest Biol. Technol. 95: 42-45.

Sisler, E.C., Dupille, E., Serek, M. 1996. Effect of 1-methylcyclopropene and methylenecyclopropane binding and ethylene action on cut carnations on ethylene. Plant Growth Regul. 18: 79-86.

Tanaka, F., Imamura, K., Tanaka, F., Uchino, T. 2018a. Determination of thermal diffusivity of persimmon flesh tissue using three-dimensional structure model based on X-ray computed tomography. J. Food Eng. 221: 151-157.

Tanaka, F., Nashiro, K., Obatake, W., Tanaka, F., Uchino, T. $2018 \mathrm{~b}$. Observation and analysis of internal structure of cucumber fruit during storage using X-ray computed tomography. Engineering in Agriculture, Environment and Food 11: 51-56.

Watkins, C.B. 2006. The use of 1-methylcyclopropene (1MCP) on fruits and vegetables. Biotechnol. Adv. 24: 389-409.

Woolf, A.B., Requejo-Tapia, C., Cox, K.A., Jackman, R.C., Gunson, A., Arpaia, M.L., White, A. 2005. 1-MCP reduces physiological storage disorders of "Hass" avocados. Postharvest Biol. Technol. 35: 43-60. 
